\title{
Anaemia among non-pregnant women in rural Bangladesh
}

\author{
SM Ziauddin Hyder ${ }^{1,2, *}$, Lars-Åke Persson ${ }^{2,3}$, AMR Chowdhury $^{1}$ and \\ Eva-Charlotte Ekström ${ }^{2,4}$ \\ 'BRAC, 75 Mohakhali, Dhaka 1212, Bangladesh: ${ }^{2}$ Epidemiology Department of Public Health and Clinical \\ Medicine, Umeå University, Umeå S-90185, Sweden: ${ }^{3}$ Public Health Sciences Division, ICDDR, B, Centre for Health \\ and Population Research, Dhaka 1212, Bangladesh: ${ }^{4}$ Clinical Sciences Division, ICDDR, B, Centre for Health and \\ Population Research, Dhaka 1212, Bangladesh
}

Submitted October 1999: Accepted August 2000

\begin{abstract}
Objective: To estimate the prevalence and severity of anaemia among non-pregnant women in rural Bangladesh and describe its social distribution.

Design: A cross-sectional study conducted in February-March 1996. Haemoglobin concentration was measured on a capillary blood sample by cyanmethaemoglobin method. The World Health Organization (WHO) classification was used to define anaemia.

Setting: Twelve randomly selected villages in Fulbaria thana of Mymensingh district, about $110 \mathrm{~km}$ northwest of Dhaka city in Bangladesh.

Subjects: A systematically selected sample of 179 non-pregnant apparently healthy women aged 15-45 years.

Results: Anaemia was highly prevalent (73\%; 95\%CI 67-79\%). Most of the women had mild (52\%) or moderate (20\%) anaemia, but a few of them suffered from severe anaemia (1\%). Ascaris was common (39\%) while hookworm was not (1\%). The anaemia prevalence had no statistically significant association with age, parity or Ascaris infestation $(P>0.05)$. Women with less than 1 year of schooling, who were landless or who reported having an economic deficit in the household had significantly higher prevalence of anaemia $(P<0.05)$. There was a significantly increasing trend in anaemia prevalence with decreasing socioeconomic situation (SES). However anaemia was common in all social strata.

Conclusions: Although the overall anaemia prevalence among non-pregnant rural women is high, only a few women suffer from severe anaemia. Women of all SES groups irrespective of their age and parity are affected by anaemia.
\end{abstract}

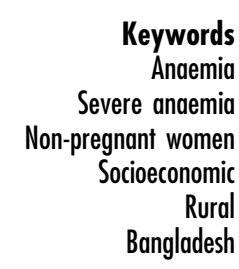

Anaemia is a major public health problem. It has been estimated that 2150 million people in the world are anaemic, of whom about 50\% are thought to suffer from iron deficiency anaemia ${ }^{1}$. Iron deficiency and anaemia are most prevalent among pregnant women and young children with the highest prevalence in low income countries $^{2}$. Iron deficiency and anaemia during pregnancy are associated with low birth weight, preterm delivery and increased perinatal mortality ${ }^{3-5}$. Routine supplementation of iron through the primary health care system has been widely practised to reduce maternal anaemia, although the programmes have shown limited effectiveness ${ }^{6,7}$.

Women of reproductive age in low income countries who are currently not pregnant are also affected by anaemia ${ }^{8}$. The most important functional consequences are fatigue and reduced productivity 9 . However, the recent interest in iron supplementation of non-pregnant women is mostly rationalized by its potential impact on maternal anaemia. Prepregnancy haemoglobin concentration and iron status are believed to be predisposing factors for maternal anaemia.

Several studies have found a negative association between socioeconomic situation (SES) and anaemia prevalence $^{10-12}$. Women from poor households are usually found to have higher anaemia prevalence. Poor SES is known to be associated with a number of factors such as high parity, short birth interval, poor diet both in quantity and quality, lack of health and nutrition awareness, and a high rate of infectious diseases and parasitic infestations. Since SES is an important determinant of access to health care, poor people have often limited access to medical attention and preventive measures ${ }^{13}$, increasing their risk of becoming anaemic.

Bangladesh is a poor country with a present per capita gross national product of about US $\$ 280$ only. According to the latest national nutrition survey ${ }^{14}$, more than $90 \%$ of the pre-school children suffer from mild to severe 
protein-energy malnutrition. The prevalence of anaemia among rural pregnant and non-pregnant women was found to be $60 \%$ and $85 \%$, respectively ${ }^{14}$.

The government and a number of non-governmental organizations have been implementing health programmes that include prevention and control of anaemia. So far, the major intervention has been the distribution of iron/folate supplements to pregnant women. However, supplementing newly wed women has also been discussed recently.

The aim of this paper is to estimate the prevalence of anaemia and its severity among non-pregnant women in a rural area of Bangladesh, describe its socioeconomic stratification, and explore some factors commonly associated with anaemia.

\section{Subjects and methods}

The study was performed in 12 villages of Fulbaria thana (subdistrict) in Mymensingh district, Bangladesh, about $110 \mathrm{~km}$ northwest of Dhaka city. The thana was selected to represent areas covered only by government health services for women which did not have any additional antenatal health service by other providers. The study villages were selected randomly and were representative of typical rural Bangladesh. They have a high population density and are located on the plain of agricultural land. The livelihood of the population in the study area is mainly based on subsistence farming. The staple crop is rice, which is consumed with vegetables, lentils and some fish, as well as meat on rare occasions. The study was conducted in February-March 1996. This is a post-harvest period for rice and considered as the time when most of the households have the best food and economic resources. A sample of 184 women was selected based on their availability at home and consent to participate in the study. The selected women were in the age range of 15-45 years. They were all married, apparently healthy and reportedly not pregnant at the time of the study.

The study was conducted by the Research and Evaluation Division (RED) of BRAC, which is a national nongovernmental organization in Bangladesh. Twelve female interviewers of BRAC/RED received a 3-day training on application of the questionnaire. They were divided into six groups, each responsible for two villages. To identify and recruit the women from a village, each team started houseto-house visits from the centre of the village and then moved in one direction until the recruitment of the required number of 15 women was completed. This sampling method has been recommended in health studies in low income countries ${ }^{15}$.

Each woman was interviewed using a structured questionnaire. The women were provided with a plastic container to collect a sample of faeces. The next day, two laboratory technicians visited the women at their houses and picked up the stool samples. Twenty microlitre capillary blood samples were collected by fingerprick from each woman and preserved in a vial containing $5 \mathrm{ml}$ of Drabkin's solution. The samples were kept in a cold flask and then transported to Mymensingh Medical College Hospital laboratory. Haemoglobin concentration measurement was performed on the same day, using the cyanmethaemoglobin method ${ }^{16}$. Anaemia was defined as a haemoglobin concentration $<120 \mathrm{~g} \mathrm{l}^{-1}$, which was further categorized as mild (100-119 $\left.\mathrm{g} \mathrm{l}^{-1}\right)$, moderate (70-99 $\left.\mathrm{g} \mathrm{l}^{-1}\right)$ and severe $\left(<70 \mathrm{~g} \mathrm{l}^{-1}\right)^{8}$. The stool samples were diluted with sodium chloride solution and examined for the presence of hookworm ova and Ascaris by a trained laboratory technician. Of the 184 women originally selected, four refused fingerprick blood sampling and one was later found to be pregnant, leaving 179 women for final analysis.

The questionnaire included three indicators of SES: attendance in a formal school, perceived household economic status and household landholding. These indicators have been used and tested in other studies and have been found to be a valid measure of SES in rural Bangladesh ${ }^{17}$. For school attendance, a woman who did not complete at least 1 year in a formal school was categorized as having no schooling. A woman who reported that she had attended a formal educational institution for at least 1 year was categorized as having attended school irrespective of her current ability to read or write. To obtain information on perceived economic status, a woman was asked whether she considered her household's economic situation to have been always in deficit, occasionally in deficit, balanced or surplus in the preceding year. The four different options were explained to each woman and she was asked to categorize herself under one of the options. A household was categorized as 'deficit' if she answered either always deficit or occasionally deficit. The two other options were combined to a 'non-deficit' category. The third indicator of SES was household landholding. Due to diversity of local measurement units and the prevailing inheritance laws, it was often difficult to obtain reliable information on the total amount of landholding. To validate the information, the woman's answer on landholding was checked with those of other adult family members and the answer that was commonly agreed upon was recorded. Households with less than 0.5 acre (0.2 ha) of land were categorized as functionally landless. This definition of landlessness has been used to target poor households for poverty-alleviation programmes in Bangla$\operatorname{desh}^{18}$

An SES score was constructed using a combination of the previously mentioned three SES indicators. The score ranged from 0 to 3 based on the accumulated number of positive attributes. For example, a woman who reported that she had formal schooling, was economically nondeficit and had more than 0.5 acre of land, was given an SES score of 3 .

Statistical significance of association between anaemia prevalence and an individual indicator of SES was analysed 


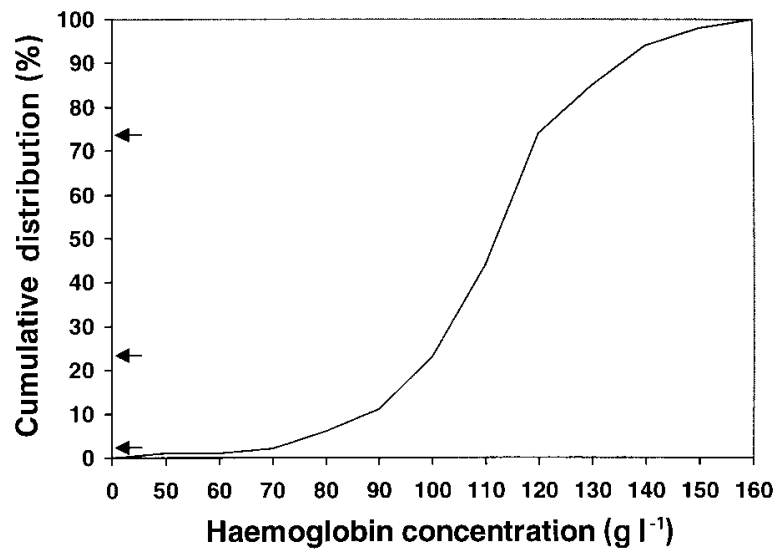

Fig. 1 Cumulative distribution of haemoglobin concentration in nonpregnant adult women in a rural area of Mymensingh, Bangladesh $(n=179)$. The proportions with severe, moderate and mild anaemia are indicated with arrows

by the chi-square test. Trend over levels of SES was evaluated by the chi-square test for trend. The association between anaemia prevalence, age, parity and Ascaris infestation was evaluated with multivariate logistic regression analysis controlling for SES. $P$ values less than 0.05 were considered as statistically significant. The SPSS WIN 8.0 software package was used for data analysis.

The study protocol was approved by the Bangladesh Medical Research Council (BMRC) ethical review committee.

\section{Results}

The mean age of the women was 28 years (SD 8 years) and they had three children on average. For women who had at least one child, the average time since the last pregnancy was 33 months. Ascaris was prevalent (39\%), while hookworm was not (1\%). A majority of the study women had no formal schooling $(66 \%)$ and more than half were landless (61\%).

Mean haemoglobin concentration of the study women was $112 \mathrm{~g} \mathrm{l}^{-1}$ (SD $18 \mathrm{~g} \mathrm{l}^{-1}$ ). The anaemia prevalence was 73\% (95\%CI 67-79\%) (Fig. 1). The prevalence of mild, moderate and severe anaemia being 52\%, 20\% and 1\%, respectively.

In a multivariate logistic regression analysis, age, parity and Ascaris infestations were not significantly associated with anaemia prevalence. This was even the case when controlling for SES. Each of the three single indicators of SES, as well as the combined SES score, were found to be significantly associated with anaemia prevalence (Table 1). Thus, women with less than 1 year of schooling, who were landless or who were economically deficit showed higher prevalence of anaemia.

Using the combined SES score, a significant trend of increasing anaemia prevalence with decreasing SES was found $(P=0.001)$ (Fig. 2). Women with the lowest SES score had an anaemia prevalence which was significantly higher than any of the other three scores $(P=0.002)$. There was no significant difference between any of the other SES categories. Out of 179 women, there were only two cases of severe anaemia and both of them were in the lowest SES group.

\section{Discussion and conclusions}

The results in this study are based on a cluster sampling procedure $^{15}$. Measures were taken to ensure that the selected sample was representative of the non-pregnant population of the study villages. The villages were randomly selected. The selection of women was systematic and was done to avoid selection bias. The procedure provided an equal opportunity for women of different socioeconomic settings to be included in the study. Availability of the women around their houses and their consent to participate were the factors which determined their inclusion in the study. In the rural setting of Bangladesh, most women are present around their houses and the cultural practice is for men to be responsible for most of the outside activities including food purchase.

Table 1 Anaemia prevalence by socioeconomic situation $(n=179)$

\begin{tabular}{|c|c|c|c|c|}
\hline Characteristics & $n$ & Anaemia prevalence (\%) & $95 \% \mathrm{Cl}$ & $P$ value* \\
\hline \multicolumn{5}{|l|}{ Education } \\
\hline No formal schooling & 118 & 78 & $71-85$ & \\
\hline With formal schooling & 61 & 62 & $50-74$ & 0.03 \\
\hline \multicolumn{5}{|l|}{ Land holding (decimals) } \\
\hline Landless $<50$ & 109 & 79 & $71-87$ & \\
\hline With land 50+ & 70 & 63 & $52-74$ & 0.02 \\
\hline \multicolumn{5}{|c|}{ Perceived economic situation } \\
\hline Deficit & 89 & 82 & $74-90$ & \\
\hline Non-deficit & 90 & 63 & $53-73$ & 0.007 \\
\hline \multicolumn{5}{|l|}{ SES score } \\
\hline 0 (low SES) & 58 & 88 & $80-96$ & \\
\hline 1 & 53 & 72 & $60-84$ & \\
\hline 2 & 36 & 61 & $45-77$ & \\
\hline 3 (high SES) & 32 & 59 & $42-76$ & 0.007 \\
\hline
\end{tabular}




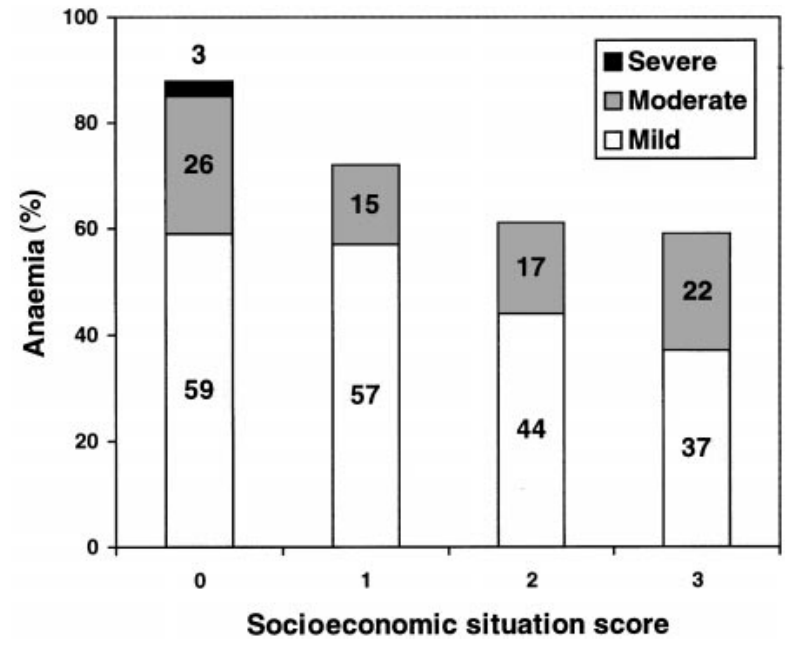

Fig. 2 Anaemia prevalence in non-pregnant women in a rural area of Bangladesh by socioeconomic score $(n=179)$. Lowest SES score $=0$ and highest SES score $=3$

However, two categories of women may stay out during the day, mainly because of their occupational involvement. The first group comprises the economically weaker segment of the rural population who are known to be ultra poor and are often engaged in manual labour for survival. The second group comprises women from relatively better off families who are at least high school graduates and are engaged in professions such as teaching in a primary school located in the same village. Although they are small in number, we may have missed a few women from both these groups. The women represent different ends of the anaemia spectrum and it is likely that in part an under- or overestimation is balanced.

The study villages have features characteristic of the rest of the rural areas of Bangladesh, namely dense population, high illiteracy, agriculture-based livelihood and government-run regular health care services. Thus, there are reasons to believe that the sample villages are fairly representative of rural Bangladesh. The study was performed in the post-harvest season, when food availability is better than at other periods of the year. The seasonal variation in anaemia prevalence in Bangladesh is unknown, but, if present, would imply a possible underestimation of the average annual prevalence.

The prevalence of anaemia among non-pregnant rural women was found to be $73 \%$, which is about two-fold higher than the global prevalence in the same population group ${ }^{8}$. The prevalence is of the same magnitude as found in the latest national nutrition survey in areas around Mymensingh ${ }^{14}$, indicating that anaemia is indeed a widespread public health problem in Bangladesh. Although an association between anaemia prevalence and SES was found, it was common in all SES groups. When the SES score was analysed separately for mild or moderate anaemia, no statistically significant association was found. Because of the overall high prevalence and the lack of SES clustering of mild and moderate anaemia, any future anaemia prevention and control measure should, therefore, address the whole population and not be selective in terms of SES in a rural community.

Severe anaemia has been suggested to be associated with a high risk of maternal mortality ${ }^{19,20}$. It has been calculated that severe anaemia is associated with a 4.5 -fold risk of maternal death in low income countries ${ }^{21}$. In our study, however, the prevalence of severe anaemia was found to be very low. Although no national estimate is available, several studies have indicated that severe anaemia among women in Bangladesh is rare ${ }^{22-24}$, which is supported by our study. This can be contrasted with the high prevalence found in neighbouring India where the rate of severe anaemia has been reported to be $2-27 \% 0^{25-27}$, suggesting wide geographical differences in anaemia prevalence and factors contributing to the problem. Severe anaemia among women may have multiple causes ${ }^{28}$. Since hookworm, malaria and human immunodeficiency virus (HIV) infections are each associated with high anaemia prevalence ${ }^{29-32}$, areas where more than one of these causes are prevalent can be expected to have a higher prevalences of severe anaemia. The prevalences of hookworm infestation, malaria and HIV infections are apparently higher in India ${ }^{33-35}$ than in Bangladesh. The prevalence of hookworm infestation was low in Mymensingh and it was reported by the district health office that there were no reported cases of malaria or HIV infections.

Despite the absence of these major contributory factors, it is surprising to notice a very high prevalence of mild to moderate anaemia among the women. The diet in rural Bangladesh is largely dominated by foods of plant origin, contributing more than $86 \%$ of the total energy ${ }^{14}$. Since dietary iron of plant origin has a low bioavailability ${ }^{36}$, this may be considered to be one of the contributing factors, along with limited consumption of animal products. Other important factors for anaemia include chronic proteinenergy deficiency, other micronutrient deficiencies and chronic infections.

The associations between anaemia and parity and age, which have been observed in studies in other low income countries $^{37,38}$, were not demonstrated in our study. This may, at least partly, be due to a limited sample size. A difference in prevalence between younger (15-24 years) and older (35-44 years) women of $25 \%$ could have been demonstrated. Thus, smaller age or parity differences could not be shown due to the size of the sample. However, a study done on healthy non-pregnant Indian Hindu and Muslim women in Fiji ${ }^{39}$, and another done in Buenos Aires ${ }^{10}$, did not find any such association either.

Our study points out that anaemia is highly prevalent among non-pregnant women in rural Bangladesh, but the prevalence of severe anaemia is low. Women of all SES groups are affected by anaemia irrespective of age and parity. It is important to identify the causes of anaemia so that the problem can be addressed in the most effective way. 


\section{Acknowledgements}

Dr Sadia A. Chowdhury and other colleagues at the Health and Population Division, BRAC are acknowledged for their co-operation in the fieldwork. Professor Abdullah Akhter and Dr Akram Hossain, Department of Microbiology, Mymensingh Medical College, Bangladesh collaborated in the laboratory activities.

\section{References}

1 DeMaeyer E, Adiels-Tegman M. Prevalence of anaemia in the world. World Health Stat. Q. 1985; 38: 302-16.

2 DeMaeyer EM. Preventing and Controlling Iron Deficiency Anaemia through Primary Health Care. A Guide for Health Administrators and Programme Planners. Geneva: World Health Organization, 1989.

3 Scholl T, Hediger M, Fischer R, Shearer J. Anemia vs iron deficiency: increased risk of preterm delivery in a prospective study. Am. J. Clin. Nutr. 1992; 55: 985-8.

4 Lieberman E, Ryan K, Monson R, Schoenbaum S. Association of maternal hematocrit with premature labor. Am. J. Obstet. Gynecol. 1988; 159: 107-14.

5 Murphy J, O'Riordan J, Newcombe R, Coles E, Pearson J. Relation of haemoglobin levels in first and second trimesters to outcome of pregnancy. Lancet 1986; i: 992-4.

6 Schultink W, van der Ree M, Matulessi P, Gross R. Low compliance with an iron supplementation programme: a study among pregnant women in Jakarta, Indonesia. Am. J. Clin. Nutr. 1993; 57: 135-9.

7 WHO. Iron Supplementation during Pregnancy: Why aren't Women Complying? A Review of Available Information. Geneva: World Health Organization, 1990.

8 WHO. The Prevalence of Anaemia in Women. A Tabulation of Available Information. Geneva: World Health Organization, 1992.

9 Untoro J, Gross R, Schultink W, Sediaoetama D. The association between BMI and haemoglobin and work productivity among Indonesian female factory workers. Eur. J. Clin. Nutr. 1998; 52: 131-5.

10 Carlo EB, Sosa EM. Iron status in non-pregnant women of child bearing age living in greater Buenos Aires. Eur. J. Clin. Nutr. 1991; 45: 215-20.

11 Isah HS, Fleming AF, Ujah IAO, Ekwempu CC. Anaemia and iron status of pregnant and non-pregnant women in the Guinea savanna of Nigeria. Ann. Trop. Med. Parasitol. 1985; 79: 485-93.

12 Johnson A, Latham MC, Roe DA. The prevalence and etiology of the nutritional anemias in Guyana. Am. J. Clin. Nutr. 1982; 35: 309-18.

13 Lovell C, Abed FH. Scaling up in health: two decades of learning in Bangladesh. In: Rohde J, Chatterjee M, Morley D, eds. Reaching Health for All. Bombay: Oxford University Press, 1988: 212-32.

14 Jahan K, Hossain M. Nature and Extent of Malnutrition in Bangladesh: Bangladesh National Nutrition Survey 1995-96. Dhaka: Institute of Nutrition and Food Science, Dhaka University, 1998.

15 Bennett S, Woods T, Liyanage WM, Smith DL. A simplified general method for cluster sample surveys of health in developing countries. World Health Stat. Q. 1991; 44: 98-106.

16 INACG. Measurement of iron status. Washington, DC: International Nutritional Anemia Consultative Group, 1985.

17 BRAC. Baseline Survey Report. BRAC-ICDDR, B Joint Research Project in Matlab. Dhaka: Research and Evaluation Division, BRAC, 1994.
18 BBS. Report of the Poverty Monitoring Survey. Dhaka: Bangladesh Bureau of Statistics, 1998.

19 UN ACC/SCN 24th Session. Report of the Working Group on Iron Deficiency. Geneva: United Nations Administrative Committee on Coordination/Subcommittee on Nutrition, 1997.

20 Jackson DJ, Klee EB, Green SD, Mokili JL, Elton RA, Cutting WA. Severe anaemia in pregnancy: a problem of primigravidae in rural Zaire. Trans. R. Soc. Trop. Med. Hyg. 1991; 85: 829-32.

21 Rush D. Nutrition and Maternal Mortality in the Developing World. Boston: Tufts University, 1998 (mimeograph).

22 Ahmed F. Prevention and Aetiology of Anaemia in Pregnancy in Bangladesh. Dhaka: Institute of Nutrition and Food Science, University of Dhaka, 1998 (mimeograph).

23 Husain MM, Rashid MA, Ali SMK. Aetiology of Anaemia in Bangladesh. Dhaka: Institute of Epidemiology and Disease Control Research, 1997 (mimeograph).

24 Islam AIM, Siddaqua R, Rahman A, Rahman A, Ara I. Iron deficiency anaemia in pregnancy. Bangladesh Med. Res. Counc. Bull. 1977; 3: 1-8.

25 Krishnaswamy K, Bhaskram P, Brahman GNV. Iron deficiency Anaemia in Pregnancy - Prevention and Control Strategies in India. Hyderabad: National Institute of Nutrition, 1998 (mimeograph).

26 Kumar R, Sharma AK, Barik S, Kumar V. Maternal mortality inquiry in a rural community of north India. Int. J. Gynecol. Obstet. 1989; 29: 313-9.

27 Bhatia JC, Cleland J, Bhagavan L, Rao NS. Levels and determinants of gynecological morbidity in a district of South India. Stud. Fam. Plann. 1997; 28: 95-103.

28 Fleming AF. The aetiology of severe anaemia in pregnancy in Ndola, Zambia. Ann. Trop. Med. Parasitol. 1989; 83: 37-49.

29 Atukorala TM, de Silva LD, Dechering WH, Dassenaeike TS, Perera RS. Evaluation of effectiveness of iron-folate supplementation and anthelmintic therapy against anemia in pregnancy - a study in the plantation sector of Sri Lanka. Am. J. Clin. Nutr. 1994; 60: 286-92.

30 Olukoya AA, Abidoye RO. A study of intestinal parasites in antenatal clinic patients in Lagos. Health Hyg. 1991; 12: 176-9.

31 Brabin BJ, Ginny M, Sapua J, Galme K, Paino J. Consequences of maternal anaemia on outcome of pregnancy in a malaria endemic area in Papua New Guinea. Ann. Trop. Med. Parasitol. 1990; 84: 11-24.

32 McDermott JM, Slutsker L, Steketee RW, Wirima JJ, Breman JG, Heymann DL. Prospective assessment of mortality among a cohort of pregnant women in rural Malawi. Am. J. Trop. Med. Hyg. 1996; 55: 66-70.

33 Ananthakrishnan S, Nalini P, Pani SP. Intestinal geohelminthiasis in the developing world. Natl. Med. J. India 1997; 10: 6771.

34 Kochar DK, Thanvi I, Joshi A, Subhakaran Aseri S, Kumawat BL. Falciparum malaria and pregnancy. Indian J. Malariol. 1998; 35: 123-30.

35 Kumar RM, Khuranna A. Pregnancy outcome in women with beta-thalassemia major and HIV infection. Eur. J. Obstet. Gynecol. Reprod. Biol. 1998; 77: 163-9.

36 Gillooly M, Bothwell TH, Torrance JD, MacPhail AP, Derman DP, Bezwoda WR. The effects of organic acids, phytates and polyphenols on the absorption of iron from vegetables. $\mathrm{Br}$. J. Nutr. 1983; 49: 331-42.

37 Desalegn S. Prevalence of anaemia in pregnancy in Jima town, South Eastern Ethiopia. Ethiop. Med. J. 1993; 31: 2518 .

38 Johnson AA, Latham MC, Roe DA. The prevalence and the aetiology of the nutritional anemia in Guyana. Am. J. Clin. Nutr. 1982; 35: 309-18.

39 Buchanan JG, Nixon AD, Pettit JE, et al. Iron deficiency and anaemia among Indian women in Fiji. Pathology 1982; 14: 269-75. 